\title{
DUAS PLANTAS HOSPEDEIRAS NOVAS DO NEMATÓIDE MELOIDOGYNE COFFEICOLA *
}

Luiz Gonzaga E. LORDEllo

RubENS R. A. LORDELlo ***

Dr. EUGÊNIO KROL REBEL, eng. agrônomo do Instituto Brasileiro do Café, com sede em Maringá, PR, gentilmente remeteu para estudo em nosso Departamento uma coleção de raízes de cafeeiros novos crescidos em solo infestado por nematóides. Ao examinar o valioso material, verificamos que Meloidogyne coffeicola Lordello \& Zamith, 1960, aparecia parasitando duas plantas ainda não referidas como hospedeiras desse danoso nematóide. Realmente, desde que LORDELLO \& ZAMITH (1960) descreveram a espécie, ela não foi jamais referida em outra cultura, além de Coffea arabica.

As plantas parasitadas por M. coffeicola, presentes na coleção remetida por REBEL, foram Coffea dewevrei var. excelsa e Coffea canephora var. robusta. Aliás, um dos materiais desta última espécie (café robusta) apresentavase atacado também por M. javanica (Treub, 1885) Chitwood, 1949, confirmando observações anteriores (LORDELLO, 1972; MORAES \& cols., 1972).

Examinando, ao microscópio entomológico, as raízes parasitadas, pudemos verificar que os nematóides se localizavam apenas na raiz principal, e não nas laterais. $O$ córtex das partes atacadas apresentava-se intensamente fendido e, em consequiência, descolado dos tecidos subjacentes. Áreas de tecidos escurecidos, necróticos, mais ou menos extensas, puderam ser divisadas ao longo de diversas raízes.

\section{SUMMARY}

Coffea dewevrei var. excelsa and Coffea canephora var. robusta are recorded as new hosts for Meloidogyne coffeicola (Nemata, Hete-

* Entregue para publicação em 31/10/72.

* Departamento de Zoologia. ESALQ.

*** Bolsista do Instituto Brasileiro do Café. 
roderidae). Robusta coffee was found also attacked by M. javanica. Symptoms shown by roots are described.

\section{LITERATURA CITADA}

LORDELLO, L. G. E., 1972 - Nematode pests of coffee. Em "Economic Nematology", J. M. Webster ed., Academic Press, Londres, pp. 268-284.

LORDELLO, L. G. E. \& A. P. L. ZAMITH, 1960 - Meloidogyne coffeicola sp. n., a pest of coffee trees in the State of Paraná, Brazil (Nemata, Heteroderidae). Rev. Brasil. Biol. 20(4):375-379.

MORAES, M. V. de, L. G. E. LORDELLO, O. A. PICCININ \& R. R. A. LORDELLO, 1972 - Pesquisas sobre plantas hospedeiras do nematóide do cafeeiro, Meloidogyne exigua Goeldi, 1887. Ciência e Cultura 24(7):658-660. 